\title{
TAMPILAN KUALITATIF DAN ANALISIS KORELASI UKURAN TUBUH SAPI BALI JANTAN
}

\author{
Qualitative Characteristics and Body Size Correlation Analysis \\ of Male Bali Cattle
}

\author{
Adelia Domili ${ }^{1}$, Zulkarnain Gobel ${ }^{1}$ Fahria Datau ${ }^{2}$, Suparmin Fathan ${ }^{2}$ \\ Nibras K. Laya ${ }^{2}$, dan *Safriyanto Dako ${ }^{2}$ \\ ${ }^{1}$ Program Sarjana Jurusan Peternakan Fakultas Pertanian Universitas Negeri Gorontalo \\ ${ }^{2} J u r u s a n$ Peternakan Fakultas Pertanian Universitas Negeri Gorontalo \\ Author: email:adeliadomili9@gmail.com \\ *Corresspondance Author: email: sdako@ung.ac.id
}

\begin{abstract}
ABSTRAC
The purpose of this study was to determine the qualitative appearance and correlation analysis of male Bali cattle body size. The study used 100 male Bali cattle aged 2-3 years, the research observations focused on the qualitative character, size and body shape of male Bali cattle. Descriptive analysis was used to analyze the appearance of coat color, color patterns, horns and dorsal lines, while correlation analysis was used to determine the relationship between size and body shape of male Bali cattle. The coat color of the male Bali cattle was found to be brick red, brown, dark brown, blackish brown and black. The boundaries of the white pattern on the legs and butt mirrors are clearly visible or there are no deviations, and the population as a whole has horns.

The average body weight of bali cattle is $177.38 \pm 20.21 \mathrm{~kg}$ and has a strong correlation with chest circumference, body length, hip width and height. Male Bali cattle in Atinggola District have normal body color and color patterns, horns, sagging, body weight $177.38 \pm 20.31 \mathrm{~kg}$, body height $110.40 \pm 6.31$, chest circumference $138.70 \pm 5.33$, the level of diversity in body size and shape varies from $5.11-20.21 \%$ and the value varies from 5.11 to $20.21 \%$ and Correlation vaule $0.22-0.85$
\end{abstract}

Key words: Color and color pattern, body size, correlation, male Bali cattle

\begin{abstract}
ABSTRAK
Tujuan penelitian ini untuk mengetahui tampilan kualitatif dan analisis korelasi ukuran tubuh sapi Bali jantan. Penelitian menggunakan 150 ekor ternak sapi Bali jantan umur 2-3 tahun, pengamatan penelitian terfokus pada sifat kualitatif dan ukuran dan bentuk tubuh ternak. Analisis deskriptif dan korelasi digunakan untuk menganalisis tampilan kualitatif dan korelasi ukuran tubuh sapi Bali jantan. Warna bulu tubuh sapi Bali jantan terdiri merah bata, coklat, coklat tua, coklat kehitaman dan hitam. Batas pola warna tubuh pada bagian kaki dan cermin pantat terlihat jelas, tidak mengalmi perubahan atau penyimpangan, dan populasi secara keseluruhan memiliki bentuk tanduk berada dalam persesuai dengan, tubuh sapi bali bulu. Rataan bobot badan sapi bali sebesar $177.38 \pm 20.21 \mathrm{~kg}$ dan berkorelasi kuat terhadap Lingkar dada, Panjang badan, lebar panggul dan tinggi badan. Sapi bali Jantan di Kecamatan Atinggola memiliki warna dan pola warna tubuh normal, bertanduk, bergelambir, bobot badan $177.38 \pm 20.31 \mathrm{~kg}$, Tinggi badan $110.40 \pm 6.31$, lingkar dada $138.70 \pm 5.33$, tingkat keragaman ukuran dan bentuk tubuh bervariasi 5.11-20.21\% dan Nilai korelasi 0.22-0.85
\end{abstract}

Kata Kunci : Warna dan Pola warna, Ukuran tubuh, Korelasi, Sapi Bali jantan,

Cara Mengutip (APA Citation Style)

Domili A., Gobel Z, Datau F, Fathan S, Laya N. K, dan Dako, S. 2021. Tampilan Kualitatif dan Analisis Korelasi Ukuran Tubuh Sapi Bali Jantan. Jambura Journal of Animal Science, 4(1), 15-21 


\section{PENDAHULUAN}

Masyarakat konsumen lebih menyukai daging segar daripada hasil daging olahan sehingga mempengaruhi tingkat pemetongan dan perdagangan ternak sapi. Masyarakat perkotaan paling banyak membutuhkan daging sehingga harus di penuhi dari daerah sentra produksi sapi potong dan melibatkan perdagangan sapi potong antar daerah (Ilham \& Yusjda 2004). Salah satu penyedia daging sapi local adalah sapi Bali.

Atinggola merupakan salah satu Kecamatan di Kabupaten Gorontalo utara memiliki ternak sapi sebesar 2873 ekor atau $8.79 \%$ dari total ternak sapi yang ada di Kabupaten Gorontalo Utara (BPS,2020), dan $40-50 \%$ ternak adalah sapi bali yang ada. Kegiatan pemeliharaan sapi bali didaerah ini masih sebatas sampingan, sebagai tabungan untuk mengatasi kebutuhan dana dalam jumlah yang besar, karena semakin banyak ternak yang dimiliki dapat sewaktu-waktu dipasarkan, sehingga dapat mengatasi masalah dari petani-peternak, seperti hajatan dan sebagainya.

Ternak sapi bali yang banyak di perjual belikan adalah sapi bali jantan, karena ternak ini cepat bertumbuh dan memiliki nilai ekonomi yang lebih tinggi dibandingkan sapi Bali betina. Jika ditelaah kegiatan pemeliharaan ini merupakan usaha pembibitan yang paling sederhana. Untuk meningkatkan ekonomi petaniternak, jumlah ternak serta mengatasi pengagguran salah satunya adalah melakukan kegiatan usaha pembibitan sapi bali (Sonbait et al. 2011), sehingga, perlu adanya informasi genetic terhadap sifatsifat yang bernilai ekonomibaik secara kualitatif dan kuantitatif dari populasi ternak sapi bali. Tampilam tubuh ternak yang nampak dari luar adalah Karakteristik fenotip yang teramati secara langsung seperti warna dan pola warna tubuh, perkembangan tanduk, dan sebagainya (Laya et al, 2020; Naufal et al. 2016). Kondisi ternak sapi Bali jantan di Kecamatan Atinggola memiliki ukuran tubuh yang berbeda-beda dan warna bulu bervariatif, diduga sebagai akibat oleh kemunduran genetik, sistim pemeliharaan yang tradisional, yang mengakibatkan perbedaan produktivitas ternak. Tujuan penelitian ini adalah untuk mengetahui tampilan kualitatif dan analisis korelasi kuantitatif sapi Bali jantan.

\section{METODE PENELITIAN}

Selama 2 bulan, sejak bulan JuniJuli 2021, penelitian ini telah dilaksanakan, bertempat di Kecamatan Atinggola, Kabupaten Gorontalo Utara, Gorontalo. Alat dan bahan yang digunakan pada penelitian adalah Sapi bali sebanyak 150 ekor berumur 2-3 tahun, Pita ukur (merek Rundo), Tongkat ukur (cm), alat tulis dan Kamera digital (sony)

\section{Metode Penelitian}

Metode survey dan pengamatan langsung digunakan dalam penelitian ini. Pengamatan dilakukan terhadap ternak sapi Bali jantan dan petrernak di Kecamatan Atinggola di 4 desa yang memiliki jumlah dan tingkat kepadatan ternak yang lebih tinggi dibanding desa lainnya. Pengamatan sapi Bali jantan difokuskan untuk warna bulu, garis punggung, warna kaos kaki, warna moncong, dan warna cermin pantat. Pengukuran sifat kuantitatif dengan cara mengukur dimensi panjang kepala, lebar kepala, lingkar dada, panjang badan, lebar pinggul, tinggi punduk, tinggi pinggul, lebar gelambir, panjang gelambir (Hikmawaty, dkk, 2014; Syaiful, dkk, 2020)

\section{Analisis Data}

Data sifat kualitatif dan kuantitatif yang diperoleh dari hasil observasi dianalisis secara deskriptif sesuai petunjuk Noor, (2008); Hermanto. Dkk, (2013); dan Dako, (2019) sebagai berikut:

\section{Frekuensi genotip $=\sum$ Sifat A $\times 100 \%$}

Keterangan :

A = Salah satu sifat kualitatif pada sapi Bali jantan yang di amati

$\mathrm{n}=$ Total sampel sapi Bali jantan yang diamati 
Keeratan antara ukuran-ukuran tubuh dan bobot badan mengikuti petunjuk (Alhamda 2016); (Laya et al.,
2020) ; (Wiyanto, 2021);(Abadi et al., 2020) sebagai berikut:

Keterangan:

$$
r_{x y}=\frac{n \sum x_{i} y_{i}-\left(\sum x_{i}\right)\left(\sum x_{i}\right)}{\sqrt{\left\{n \sum x_{1}^{2}-\left(\sum x_{1}\right)^{2}\right\}}\left\{n \sum y_{1}^{2}-\left(\sum y_{1}\right)^{2}\right\}}
$$

$\mathrm{r}_{\mathrm{xy}}=$ nilai Korelasi ( $\mathrm{x}$ terhadap , ,

$\mathrm{x}=$ Ukuran-ukuran tubuh

$\mathrm{y}=$ Bobot badan

HASIL DAN PEMBAHASAN

Tampilan Kualitatif Sapi Bali Jantan

Warna dan pola warna bulu tubuh, bertanduk dan tidak bertanduk seekor ternak merupakan sifat genetic genetic yang terekspresi ternak. Ekspresi sifat kualitatif di sebabkan adanya interaksi sepasang gen yang berinteraksi saling mempengaruhi dan diwariskan pada keturunannya. Beberapa sifat kualitatif sapi Bali disajikan pada tabel 1.

Tabel 1. Sifat kualitatif Sapi bali jantan berasal dari Kecamatan Atinggola Kab. Gorontalo Utara

\begin{tabular}{|c|c|c|c|}
\hline No & Sifat kualitatif & Frek fenotipe & Ket \\
\hline & Warna Bulu Tubuh & $\mathrm{N}=150$ & \\
\hline 1 & Merah bata & 0.03 & \\
\hline 2 & Coklat & 0.11 & \\
\hline 3 & Coklat Tua & 0.23 & \\
\hline 4 & Coklat Kehitaman & 0.49 & \\
\hline \multirow[t]{2}{*}{5} & Hitam & 0.06 & \\
\hline & Garis Punggung & & \\
\hline 1 & Tebal & 0.83 & \\
\hline 2 & Sedang & 0.11 & \\
\hline \multirow[t]{2}{*}{3} & Tipis & 0.06 & \\
\hline & Warna Kaos kaki & & \\
\hline 1 & Putih berbatas & 0.71 & \\
\hline \multirow[t]{2}{*}{2} & Putih tidak berbatas & 0.29 & \\
\hline & Cermin Pantat & & \\
\hline 1 & Putih berbatas & 0.74 & \\
\hline \multirow[t]{2}{*}{2} & Putih tidak berbatas & 0.26 & \\
\hline & Moncong & & \\
\hline 1 & Putih & 0.00 & \\
\hline 2 & Hitam & 100.00 & \\
\hline \multirow[t]{2}{*}{3} & Campuran & 0.00 & \\
\hline & Bentuk Tanduk & & \\
\hline 1 & Melelengkung keatas & 76.71 & \\
\hline 2 & Melelengkung kedepan & 19.15 & \\
\hline 3 & Melengkung kebelakang & 4.14 & \\
\hline 4 & Bertanduk & 100 & \\
\hline \multirow[t]{2}{*}{5} & Tidak bertanduk & 0 & \\
\hline & Gelambir & & \\
\hline 1 & Bergelambir & 100 & \\
\hline 2 & Tidak Bergelambir & 0 & \\
\hline
\end{tabular}

\section{Data olahan 2021}

Tabel 1 Warna bulu tubuh sapi bali jantan yang berasal dari kecamatan Atinggola Kabupaten Gorontalo Utara dtemukan berwarna merah bata, coklat, coklat tua, coklat kehitaman dan hitam. Warna bulu tubuh dominan coklat kehitaman sebesar $49 \%$. Batas pola warna bagian kaki dan cermin pantat warna putih dari sapi bali terlihat berbatas jelas, masing-masing $74 \%$, dan $71 \%$, sedang tidak berbatas/batas tidak jelas masingmasing 29\% dan 26\%. Sifat ini tidak mengalami perubahan atau penyimpangan, Keseluruhan sapi bali 
jantan ditemukan memiliki tanduk yang bervariasi $4.14-76.71 \%$, bergelambir, garis punggung dominan bergaris hitam dan tebal. Tampilan sifat genetic sapi Bali yang berasal dari Kecamatan Atinggola sesuai dengan standar SNI 7355:2008 dan KEPMEN No 25/Kpts/OT.140/1/2010 sapi Bali (BSNI, 2008; Kemenpan, 2010). Hal ini menggambarkan ternak sapi bali yang berasal dari Kecamatan Atinggola memiliki genetic yang murni, berdasarkan wawancara dengan peternak sapi bali yang dimilikinya tidak dikawinkan dengan jenis sapi lainnya. Hasil penelitian ini juga memiliki kesamaan dengan yang di laporkan oleh Rajab (2021) sapi Bali yang berasal dari peternakan rakyat kampung Kalobo, distrik Salawati Utara, Kabupaten Raja Ampat tidak ditemukan warna dan pola warna tubuh yang menyimpang. Salah satu menjaga kemurnian populasi ternak adalah mengawinkan ternak antara populasi yang memiliki hubungan kekerabatan (Warwick, dkk 1990; Noor, 2008; Dako, 2019). Hasil penelitian ini berbeda dengan berbeda dengan Supriyantono dan Hakim (2008) sapi bali jantan yang berasal dari Provinsi Bali memiliki penyimpangan terhadap warna dan pola warna bulu tubuh sebesar $2 \%$. Perbedaan ini dimungkinkan karena adanya sumber bibit yang berbeda.
Sumber bibit sapi Bali yang masuk di Gorontalo Utara berasal dari Provinsi Sulawesi Tengah, sedangkan di Pulau bali merupakan sentra pembibitan sapi Bali, yang bertujuan pemurnian genetic sapi bali, sehingga perkawinan inbreeding lebih tinggi. Perkawinan inbreeding dalam populasi dapat meningkatkan homozigot gen, yang berakibat turunnya kemampuan adaptasi, produktivitas, dan temperamen ternak, dan akhirnya berdampak pada fertilitas dan pertumbuhan (Warwick, dkk 1990)

Hasil penelitian ini juga memiliki kesamaan dengan yang di laporkan oleh Rajab (2021) sapi Bali yang berasal dari peternakan rakyat kampung Kalobo, distrik Salawati Utara, Kabupaten Raja Ampat tidak ditemukan warna dan pola warna tubuh yang menyimpang. Salah satu menjaga kemurnian populasi ternak adalah mengawinkan ternak antara populasi yang memiliki hubungan kekerabatan (Warwick, dkk 1990; Noor, 2008; Dako, 2019)

\section{Ukuran tubuh sapi Bali Jantan}

Ukuran tubuh ternak dari sapi Bali merupakan gambaran deskriptif potensi genetic yang dimiliki seekor ternak dalam populasi. Tampilan ukuran tubuh Sapi Bali jantan yang berasal dari Kecamatan Atinggola terlihat pada Tabel 2.

Tabel 2. Nilai rataan, STDVe dan Keragaman dan nilai korelasi ukuran tubuh Sapi Bali Jantan

\begin{tabular}{rlrrrr}
\hline No & Ukuran Tubuh & \multicolumn{1}{c}{ Rataan } & Cov & r & Keterangan Nilai r \\
\hline 1 & Panjang Kepala & $32.96 \pm 2.96$ & 8.99 & 0.43 & Sedang \\
2 & Lebar Kepala & $17.91 \pm 1.34$ & 7.49 & 0.37 & Rendah \\
3 & Lingkar Dada & $138.70 \pm 5.33$ & 3.84 & 0.85 & Tinggi/Erat \\
4 & Lebar Pinggul & $29.36 \pm 3.75$ & 12.76 & 0.56 & Sedang \\
5 & Panjang Badan & $101.62 \pm 6.04$ & 5.94 & 0.81 & Tinggi/Erat \\
6 & Tinggi Pinggul & $110.66 \pm 4.95$ & 4.47 & 0.66 & Tinggi/Erat \\
7 & Tinggi Badan & $112.02 \pm 6.10$ & 5.45 & 0.68 & Tinggi/Erat \\
8 & Panjang Gelambir & $28.67 \pm 5.45$ & 19.01 & 0.22 & Rendah \\
9 & Lebar Gelambir & $4.94 \pm 1.66$ & 33.60 & 0.25 & Rendah \\
10 & Bobot badan & $177.38 \pm 20.21$ & 11.39 & & \\
\hline
\end{tabular}

Data olahan 2021

Tabel 2 Menggambarkan sapi bali Jantan yang berasal dari Kecamatan Atinggola memiliki rataan bobot badan ternak sapi bali jantan $177.38 \pm 20.31 \mathrm{~kg}$. Tinggi badan sapi bali jantan sebesar

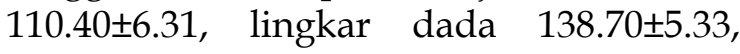
panjang gelambir, dan lebar gelambir:
$28.67 \pm 5.45,4.94 \pm 1.66$. Hasil penelitian ini berdasarkan standar SNI belum memenuhi standar. Berdasarkan standar SNI sapi Bali pada umur diatas 24 bulan memiliki panjang badan, lingkar dada dan tinggi badan masing-masing $110 \mathrm{~cm}, 155 \mathrm{~cm}$ dan tinggi pundak 107 cm (BSNI, 2010) 
Hasil penelitian ini berbeda dengan yang di laporkan Supriyantono dkk, (2014) Sapi bali dari Kampung Inam dan Jandurau, Distrik Kebar memiliki tinggi badan, panjang badan dan lingkar dada sapi jantan kelompok umur 2-3 tahun berturut-turut adalah 112,38 $\pm 9,52$; $106,90 \pm 4,76$ dan $140,80 \pm 9,28 \mathrm{~cm}$, sedangkan dari bobot badan berbeda dengan penelitian Gushairiyanto dan Depison, (2021) sapi Bali di Kabupaten Merangin dan Muaro Jambi, Provinsi Jambi memiliki bobot badan 202,04 $\pm 37,78$.

Hasil penelitian ini memiliki kesamaan dengan yang dilaporkan oleh Nurfaizin, dkk, (2019) Rata-rata bobot badan sapi bali yang berasal dari Seram Barat dan Seram Selatan sebesar 176.73$180.30 \mathrm{~kg}$, Panjang badan 110.15-112.32 cm, tinggi pundak 108.84 hingga $109.16 \mathrm{~cm}$. Perbedaan ukuran tubuh dan bobot badan pada sapi Bali jantan lebih disebabkan genetic, lingkungan (kondisi, lokasi, pakan) dan bentuk pemeliharaan (sistim pemeliharaan) yang berbeda (lokasi).

Keragaman ukuran tubuh menunjukkan perbedaan genetic dalam populasi. Berdasarkan tabel 2, Tingkat keragaman tiap ukuran dan bentuk tubuh sapi Bali jantan di Kecamatan Atinggola sangat beragam 5.11-20.21\%. Keragaman ini perbedaan ukuran dan bentuk tubuh bahkan bobot badan yang berbeda antar ternak di dalam populasi, hal ini di pengaruhi oleh factor genetic., walaupun dalam sistim pemeliharaan (tradisonal) yang dilakukan oleh peternak tidak berbeda.

Keberadaan dan perkembangan ternak sapi bali sangat ditentukan oleh genetic, lingkungan dan interaksi antar ternak.

\section{Nilai korelasi ukuran tubuh}

Korelasi ukuran tubuh sapi Bali betina memberi gambaran linieritas antar ukuran tubuh yang diamati,derajat linieritas yang dihasilkan menggambarkan kuat atau lemahnya hubungan antara ukuran tubuh yang di amati. Nilai korelasi ukuran tubuh dan bobot badan sapi Bali
Jantan memiliki keeratan hubungan dengan produktifitas dan dapat dijadikan alat seleksi produksi dalam populasi ternak sapi Bali. Berdasarkan tabel 2 Korelasi antara ukuran tubuh terhadap bobot badan sapi Bali jantan yang berasal dari Kecamatan Atinggola Kabupaten Gorontalo Utara bernilai positif, nilai korelasinya 0.22-0.85. Untuk sifat kuantitatif lingkar dada, panjang badan, tinggi badan berkorelasi positif: 0.85, 0.66, dan 0.56, terhadap bobot badan, yang ditandai dengan nilai postif, dan termasuk kategori korelasi bernilai tinggi. Hal ini disebabkan ukuran tubuh ini merupakan komponen utama yang mempengaruhi bobot badan dari ternak sapi Bali betina.

Jarak koefisien korelasi antara 0.000.20 menggambarkan hubungan korelasi rendah, jarak kolerasi antara 0.20-0.50 adalah sedang hubungan korelasi sedang, dan jarak korelasi 0.50-1.00 adalah hubungan korelasi kuat atau tinggi (Sugiyono 2015)

\section{KESIMPULAN}

Berdasarkan hasil penelitian Sapi bali Jantan di Kecamatan Atinggola memiliki cirri khas warna dan pola warna bulu tubuh yang normal, bertanduk, bergelambir, bobot badan $177.38 \pm 20.31 \mathrm{~kg}$, Tinggi badan $110.40 \pm 6.31$, lingkar dada 138.70 \pm 5.33 , tingkat keragaman ukuran dan bentuk tubuh bervariasi 5.11-20.21\%, dan Nilai korelasi ukuran tubuh terhadap bobot badan sebesar 0.22-0.85

\section{UCAPAN TERIMA KASIH}

Ucapan terima kasih disampaikan kepada Ketua Jurusan peternakan dan Dekan Fakultas Pertanian Universitas Negeri Gorontalo atas bantuan dalam pembiayaan penelitian ini melalui SKIM PENELITIAN KOLABORATIF tahun 2021.

Ucapan terimaksih juga disampaikan kepada Pemerintah Kecamatan Atinggola, Kepala Desa se-Kecamatan Atinggola, Dinas Peternakan Gorontalo Utara dan petugas penyuluh peternakan yang telah membantu mensukseskan penelitian ini 


\section{DAFTAR PUSTAKA}

Abadi, M., Nafiu, L. O., Slamet Aku, A., \& Badaruddin, R. (2020). Correlation of Body Weight and Age on The Selling Price of Bali Cattle Ranomeeto District, Konawe Selatan Regency. International Journal of Scientific Research in Science, Engineering and Technology, 4099, 26-32. https://doi.org/10.32628/ijsrset20752 1

Laya, N. K., Ibrahim, D., Dako, S., \& Datau, F. (n.d.). ANALYSIS OF THE SIZE AND BODY WEIGHT CHARACTERISTIC OF ONGOLE CATTLE THAT ARE KEPT WITH INTENSIVE AND SEMI-INTENSIVE SYSTEM. Journal of Seybold Report, 15(8), 2737-2747. https:// seyboldjournal.com/issue8page2/

Alhamda, S. 2016. Buku Ajar Metlit dan Statistik. Deepublish. Yogyakarta.

BSNI,2010. Badan Standarisasi Nasional Indonesia. Jakarta

BPS. 2018. Profil Gorontalo utara. Badan Pusat Statistika Kabupaten Gorontalo Utara.

Dako, S., Ilham, F., Laya, N. K., \& Yusuf, M. F. (2019). Manajemen pembibitan Ternak. Buku Ajar, Publisher Arthasamudra ISBN, 978-623.

Dako, S., Ilham, F., Laya, N. K., \& Yusuf, F. M. (2020). Nheritance of external genetic characteristics in chicken through triple crossing model. International Journal of Advanced Science and Technology, 29(9 Special Issue).

Gushairiyanto, G., \& Depison, D. (2021). Karakteristik Kuantitatif Sapi Bali Menggunakan Analisis Komponen Utama di Kabupaten Merangin dan
Muaro Jambi, Provinsi Jambi. Jurnal Sain Peternakan Indonesia, 16(1), 74-79.

Hermanto. H. 2013. Studi Keragaman Fenotipe Sapi Bali dan Persilangannya di Kecamatan Bunga Raya Kabupaten Siak. Skripsi. Fakultas Pertanian dan 37 Peternakan Universitas Islam Negeri Sultan Syarif Kasim Riau. Pekanbaru.

Hikmawaty, A. Gunawan, R.R. Noor, \& Jakaria. 2014. Identifikasi Ukuran Tubuh Dan Bentuk Tubuh Sapi Bali Di Beberapa Pusat Pembibitan Melalui Pendekatan Analisis Komponen Utama. Jurnal Ilmu Produksi dan Teknologi Hasil Peternakan. 02(1): 231-237.

Ilham N, Yusjda Y. 2004. Sistem transportasi perdagangan ternak sapi dan implikasi kebijakan di Indonesia. Analisis Kebijakan Pertanian. 2:37-53.

Abadi, M., Nafiu, L. O., Slamet Aku, A., \& Badaruddin, R. (2020). Correlation of Body Weight and Age on The Selling Price of Bali Cattle Ranomeeto District, Konawe Selatan Regency. International Journal of Scientific Research in Science, Engineering and Technology, 4099, 26-32. https://doi.org/10.32628/ijsrset20752 1

Laya, N. K., Ibrahim, D., Dako, S., \& Datau, F. (2020). ANALYSIS OF THE SIZE AND BODY WEIGHT CHARACTERISTIC OF ONGOLE CATTLE THAT ARE KEPT WITH INTENSIVE AND SEMI-INTENSIVE SYSTEM. Journal of Seybold Report, 15(8), 2737-2747. https:/ / seyboldjournal.com/issue8page2/

Naufal F, Setyowati EY, Suwarno N. 2016. Karakteristik kualitatif sapi Pasundan dipeternakan rakyat. Student EJournal. 5:1-13. 
Noor, R.R. 2008. Genetika Ternak. Cetakan ke-4. PT. Penebar Swadaya. Jakarta.

Nurfaizin, N., Bansi, H., \& Matitaputty, P. R. (2020, January). Karakteristik Sapi Bali Betina pada Dua Gugus Pulau di Provinsi Maluku. In Prosiding Seminar Nasional Teknologi Peternakan dan Veteriner (pp. 296-303).

Rajab, R. (2021). Karakterisasi Warna Bulu Dan Ukuran Tubuh Sapi Bali Jantan Pada Peternakan Rakyat. Jurnal Hutan Pulau-Pulau Kecil, 5(1), 97-106.

Sonbait LY, Santosa KA, Panjono. 2011. Evaluasi program pengembangan sapi potong gaduhan melalui kelompok lembaga mandiri yang mengakar di masyarakat di Kabupaten Manokwari Papua Barat. Bul Pet. 35:208-217

Sugiyono, 2015. Methode Penelitian Kuantitatif dan R\&D. Bandung Alafabeta

Supriyantono, A., \& Hakim, L. (2008). Performansi sapi bali pada tiga daerah di Provinsi Bali. Berkala Penelitian Hayati, 13(2), 147-152.

Syaiful, F. L., Khasrad, dan S. Maulida. 2020. Identifikasi Ukuran Tubuh Sapi Bali dan Simbal (Simmental-Bali) di Kecamatan Luhak Nan Duo Kabupaten Pasaman Barat. Jurnal Sain Peternakan Indonesia. 15(2): 219-222. 